\title{
CARACTERIZAÇÃo MORFOLÓGICA DE FRUTOS, SEMENTES E PLÂNTULAS DE Sesbania virgata ( CAV.) PERS ${ }^{1}$
}

\author{
ERNEIDA C. DE ARAUJO ${ }^{2}$; ANDREA VITA R. MENDONÇA²; DEBORAH G. BARROSO; \\ KELLY R. LAMÔNICA ${ }^{4}$; ROBERTO F. DA SILVA ${ }^{5}$
}

\begin{abstract}
RESUMO - A Sesbania virgata é uma espécie arbórea, pioneira e de ocorrência natural no Brasil. Pertence à família Leguminosae-Faboideae sendo recomendada para recuperação de áreas degradadas devido a sua rusticidade e capacidade de estabelecer simbiose com rizóbio. Mas, apesar de sua ampla distribuição, até o momento não havia uma descrição morfológica das estruturas de propagação e da planta na fase inicial de desenvolvimento. $O$ objetivo deste trabalho foi descrever os caracteres morfológicos dos frutos, sementes e plântulas, bem como caracterizar o processo de germinação de Sesbania virgata. Para o estudo do fruto, os seguintes aspectos foram observados: tipo; cor; dimensões; textura e consistência do pericarpo; deiscência; e número de sementes por fruto. Os aspectos observados para as sementes foram: cor; dimensões; peso de 1000 sementes; textura e consistência dos tegumentos; forma; bordo, posição do hilo e de outras estruturas presentes e características do embrião. As plântulas foram caracterizadas em dois estádios. O estádio de plântula foi considerado quando os protófilos já estavam totalmente formados e de planta jovem, a partir do surgimento do $2^{\circ}$ protófilo. Os elementos vegetativos descritos e ilustrados foram radícula, coleto, hipocótilo, cotilédones, epicótilo, protófilos e caule. O fruto de Sesbania virgata é um legume indeiscente medindo 5,8 $\mathrm{cm}$ e contendo de 2 a 6 sementes. A semente de Sesbania virgata é reniforme, endospérmica e desprovida do tegma, sendo que o hilo e o estrófíolo são facilmente distinguíveis. O eixoembrionário encontra-se inserido aos cotilédones, sendo apical e invaginado papilonáceo. A germinação da semente é do tipo epígea. A plântula jovem apresenta protófilos compostos com 4 a 9 pares de folíolos pequenos opostos e glabros com peciolo e pulvino, e no ápice há uma pequena expansão laminar glabra. A radícula é sublenhosa, de cor branca ou marrom castanho.
\end{abstract}

Termos para indexação: descrição morfológica, leguminosae, espécie arbórea.

\section{MORPHOLOGIC CARACTERIZATION OS FRUIT, SEEDS AND SEDLINGS OF Sesbania virgata ( CAV. ) PERS}

\begin{abstract}
Sesbania Virgata is a bush, pioneer and occurs naturally Brazil. It belongs to the Leguminosae-Faboideae family and is indicated for recovery-degraded areas due to its rusticity and capacity of establishing symbiosis with rhizobial. But, in spite of its wide distribution, to date there is no morphologic description of the propagation structures and the plantule. This study describes the morphologic characters of the fruits, seeds and plantules, and characterizes the germination process of Sesbania virgata. For the study of the fruit, the following aspects were observed: type; color; dimensions; texture and consistence of the pericarp; opening; and number of seeds per fruit. The aspects observed for the seeds were: color; dimensions; weigt of 1000 seeds; tegument texture and consistency; form; embroider (?), hilum and other structures position and embryo characteristics. The plantules were characterized at two stages. The plantule stage was considered when the foliage leaves were totally formed and at young plant stage starting from the appearance of the 2 nd foliage leaf. The described and cultured vegetative elements were root (main and secondary), collar, hypocotyls, cotyledons, epicotyls, foliage leaf (1st and 2nd orders) and stem. The Sesbania Virgata fruit is an indehiscent legume measuring $5,8 \mathrm{~cm}$ with 2 to 6 seeds. The Sesbania Virgata seeds are kidney-shaped and endospermic and there is no internal tegument. The hilum and the strophiole are easily distinguishable. The apical axis-embryo is inserted in the cotyledons. The seed germination is the epigeal type.
\end{abstract}

Index terms: morphologic description, leguminosae, especie bush.

\footnotetext{
${ }^{1}$ Submetido em 03/09/2003. Aceito para publicação em 24/03/2004; ${ }^{2}$ Eng $^{\mathrm{a}}$ Agr $^{\mathrm{a}}$ e doutoranda do Curso de Produção Vegetal da UENF, Campos dos Goytacazes-RJ, e-mail: erneida@uenf.br, andreavita.mendonça@bol.com.br

${ }^{3}$ Eng $^{\mathrm{a}}$ Agr $^{\mathrm{a}}$ e Prof. de Silvicultura - UENF, e-mail: deborah@uenf.br
}

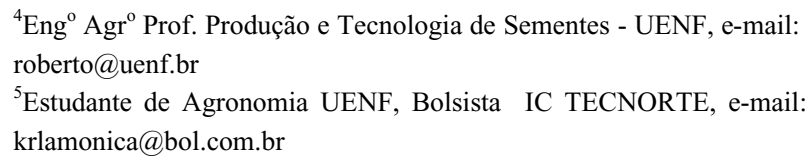




\section{INTRODUÇÃO}

A morfologia da semente é necessária nas análises de identificação e certificação da qualidade das sementes (Oliveira e Pereira, 1984). Segundo Kuniyoshi (1983), este conhecimento também pode ser aplicado no manejo, visando à conservação da fauna mediante estudos de dieta de herbívoros. Outro fato relevante é que a identificação de espécies no banco de sementes pode contribuir para melhor compreensão da regeneração e sucessão vegetal nos ecossistemas (Beltrati, 1984).

O conhecimento das características morfológicas das espécies nos estágios iniciais de crescimento propicia a identificação de espécies florestais na fase jovem, auxiliando nos estudos de regeneração natural. Kuniyoshi (1983)

Há uma carência de estudos sobre morfologia de frutos, sementes e plântulas de espécies florestais tanto nativas como exóticas. Sesbania virgata com cerca $6 \mathrm{~m}$ de altura, $25 \mathrm{~cm}$ de diâmetro a altura do peito e $5 \mathrm{~m}$ de diâmetro de copa, apresenta alta plasticidade e segundo Samôr (1999) é encontrada em margens de estradas, terrenos baldios, cavas de extração de argila e em locais próximos ao mar. Apesar de sua ampla distribuição, até o momento não havia uma descrição morfológica das estruturas de propagação e da planta na fase inicial de desenvolvimento.

Santos et al. (1997) a citam como espécie que ocorre naturalmente no Brasil, apesar de que a maior ocorrência deste gênero se dá na África.

A espécie tem vida curta, de 8 a 9 anos, com capacidade moderada de competir com gramíneas e rebrotar da cepa após corte ou fogo. Desenvolve-se naturalmente em terrenos úmidos e associa-se com Rhizobium. Trata-se de uma planta de interesse para revegetação de áreas degradadas. Pott e Pott (1994) relatam o sucesso na utilização desta espécie em ambiente ciliar. Segundo Samôr (1999) e Coutinho (2003) ela é importante na recuperação de cavas de extração de argila, em função da freqüência de ocorrência em cavas abandonadas; boa disponibilidade de sementes; e por formar simbiose radicular com rizóbio.

O presente trabalho, objetiva descrever os caracteres morfológicos dos frutos, sementes e plântulas, bem como caracterizar o processo de germinação de Sesbania virgata, de forma a contribuir com o reconhecimento da espécie em levantamentos florísticos e identificação em banco de sementes.

\section{MATERIAL E MÉTODOS}

As sementes foram manualmente retiradas dos frutos e armazenadas em ambiente de laboratório. Em seguida foram iniciadas as caracterizações e descrições dos caracteres em estudo.

\section{Caracterização dos frutos e sementes}

Foram considerados os seguintes aspectos para a caracterização do fruto: classificação do tipo; cor; dimensões (comprimento, largura e espessura); textura e consistência do pericarpo; deiscência; e número de sementes por fruto (normais e predadas). Estas avaliações e observações foram feitas mediante uma amostragem aleatória de 100 frutos.

Foram observadas características externas e internas das sementes. As características externas foram: cor; dimensões (comprimento, largura e espessura); peso de 1000 sementes (10 sub-amostras de 100 sementes); textura e consistência dos tegumentos; forma; bordo; posição do hilo e da micrópila; rafe e outras estruturas presentes. As características internas consideradas foram: embrião (cotilédones, eixo hipocótilo-radícula, plúmula) e presença de endosperma. Para permitir o estudo da morfologia interna, as sementes foram escarificadas e submersas em água à temperatura ambiente por 12 horas.

O comprimento, a largura e a espessura dos frutos e sementes foram medidos, utilizando-se um paquímetro de precisão de $0,1 \mathrm{~mm}$, sendo o comprimento medido da base até o ápice e a largura e espessura medidas na linha mediana dos frutos e sementes.

Foi adotada a terminologia para frutos e sementes constante em Vidal e Vidal (1992) e Barroso et al (1999).

Os dados das características quantitativas foram submetidos à análise descritiva, obtendo-se as respectivas médias e coeficientes de variação.

\section{Germinação}

Para avaliar o processo germinativo foram semeadas 125 sementes, distribuídas em 5 repetições de 25 sementes, em bandejas plásticas ( $35 \mathrm{~cm}$ de diâmetro interno x $15 \mathrm{~cm}$ de altura) perfuradas no fundo e preenchidas com $2 / 3$ da capacidade de seu volume com substrato comercial do tipo Plantimax. As bandejas foram colocadas sobre bancada de madeira em casa de vegetação e as plantas irrigadas diariamente. Avaliou-se a percentagem de germinação de plântulas normais e o índice de velocidade de emergência (Maguire,1962). Foram realizadas contagens diárias durante 21 dias. Determinou-se também o peso da matéria seca da parte aérea e da raiz das plântulas normais, após secagem do material em estufa de circulação forçada de ar regulada à temperatura de $80^{\circ} \mathrm{C}$ por 24 horas.

\section{Morfologia de plântula}

Para o acompanhamento do desenvolvimento das plântulas, foram obtidos 50 indivíduos por semeadura direta em bandejas com substrato comercial, dispostos no interior de uma casa de vegetação. Foram semeadas dez sementes 
de dois em dois dias para obtenção de plântulas em estádios diferentes de desenvolvimento.

O estádio de plântula foi considerado quando os protófilos encontravam-se totalmente formados, sendo o estádio de planta jovem, caracterizado a partir do surgimento do $2^{\circ}$ protófilo. Os elementos vegetativos descritos e ilustrados foram: raiz (primária e secundárias), coleto, hipocótilo, cotilédones, epicótilo, protófilos (primeiro e segundo par de protófilos ) e caule.

\section{RESULTADOS E DISCUSSÃO}

\section{Aspectos morfológicos de frutos e sementes}

$\mathrm{O}$ fruto de Sesbania virgata é um legume indeiscente e nucóide, apresentando cor verde quando jovem e marrom opaco quando maduro, textura seca, superfície rugosa, com brusco afinamento tanto da base, como da extremidade, sendo esta pontiaguda. O bordo do fruto é ondulado, havendo sutura a partir do pedúnculo até o ápice. $\mathrm{O}$ pedúnculo é consistente e lenhoso. O pericarpo, mesocarpo e endocarpo são distintos, sendo que o pericarpo é fino, o mesocarpo é branco acinzentado com consistência semelhante à cortiça e o endocarpo contém textura lisa de cor marfim. Na Figura 1 observa-se o fruto e sementes de Sesbania virginata.

A análise descritiva das dimensões do fruto $\mathrm{e}$ do número de sementes por fruto encontram-se na Tabela 1.

$\mathrm{Na}$ chave de identificação de gênero da família Leguminosae, baseada na morfologia de frutos e sementes, proposta por Barroso et al. (1999), o gênero Sesbania foi caracterizado por possuir frutos com mais de três $\mathrm{cm}$ de comprimento, o que foi observado nos frutos de $S$. virgata.

Os frutos de S. virgata continham de duas a seis sementes por fruto, sendo que em $51 \%$ dos frutos avaliados foram encontradas $100 \%$ de sementes sadias. A Figura 2 apresenta a freqüência do número de sementes por fruto.

Na Figura 3 observam-se sementes com tegumento (a), com (b) e sem testa (c). A semente é reniforme de cor castanho claro com testa lisa, polida e dura. O hilo é bem distinto, oblongo de cor variável, podendo ser branco, marrom ou um misto de marrom e branco sendo que sua posição não é apical e nem completamente mediana. $\mathrm{O}$ estrofiolo constituiu-se por uma mancha de coloração mais escura que a semente (marrom escuro). O embrião é cotiledonar sendo os cotilédones de cor amarelo claro esverdeados, membranáceo, e de bordos arredondados, quanto à posição é apical e quanto à forma é invaginado papilonáceo. $\mathrm{O}$ endosperma tem aspecto gelatinoso $\mathrm{e}$ semitransparente quando hidratado, é espesso e envolve o embrião. A Figura 3 mostra a semente desprovida de testa (b) e o embrião (d) de Sesbania.

De acordo com Barroso et al. (1999), as plantas da família Leguminosae não apresentam semente com tegumento interno, pois este é naturalmente reabsorvido. Para estes autores as plantas sub-família Faboideae apresentam sementes com hilo e estrofíolo bem distintos, e consideram ainda que o formato mais comum das sementes nesta subfamília é reniforme.

O comprimento, largura, espessura e peso de 1000 sementes encontram-se na Tabela 2.

\section{Germinação e morfologia da plântula}

Verificou-se um percentual médio de germinação aos 21 dias de $52 \%$ e um índice de velocidade de emergência (IVE) médio de 1,51. A Tabela 3 apresenta a análise

\section{TABELA 1. Dimensões médias do fruto e número de sementes / fruto de Sesbania virgata}

\begin{tabular}{lcccc}
\hline Parâmetros & $\begin{array}{c}\text { Comprimento } \\
(\mathrm{mm})\end{array}$ & $\begin{array}{c}\text { Largura } \\
(\mathrm{mm})\end{array}$ & $\begin{array}{c}\text { Espessura } \\
(\mathrm{mm})\end{array}$ & $\begin{array}{c}\text { Número de } \\
\text { sementes }\end{array}$ \\
\hline Média & 5,81 & 7,82 & 5,81 & 4,44 \\
Coeficiente de variação (\%) & 14,96 & 10,81 & 13,66 & 22,25 \\
Erro padrão da média (s) & 0,17 & 0,17 & 0,16 & 0,2 \\
\hline
\end{tabular}

TABELA 2. Dimensões médias e peso de 1000 sementes de Sesbania virgata.

\begin{tabular}{lcccc}
\hline \multicolumn{1}{c}{ Parâmetros } & $\begin{array}{c}\text { Comprimento } \\
(\mathrm{mm})\end{array}$ & $\begin{array}{c}\text { Largura } \\
(\mathrm{mm})\end{array}$ & $\begin{array}{c}\text { Espessura } \\
(\mathrm{mm})\end{array}$ & $\begin{array}{c}\text { Peso 1000 } \\
\text { sementes }(\mathrm{g})\end{array}$ \\
\hline Média & 6,87 & 4,40 & 3,32 & 7,78 \\
Coeficiente de variação (\%) & 5,58 & 4,97 & 4,43 & 2,36 \\
Erro padrão da média (s) & 0,07 & 0,05 & 0,03 & 0,13 \\
\hline
\end{tabular}

TABELA 3. Percentagem de germinação; índice de velocidade de emergência (IVE); peso seco de parte aérea e raiz (g) de plântulas de Sesbania virgata aos 21 dias após a germinação.

\begin{tabular}{lrrcc}
\hline \multirow{2}{*}{ Parâmetros } & \multirow{2}{*}{ IVE } & Germinação & \multicolumn{2}{c}{ Peso da matéria seca } \\
\cline { 4 - 5 } & & \multicolumn{1}{c}{$(\%)$} & Parte aérea $(\mathrm{g})$ & Raiz $(\mathrm{g})$ \\
\hline Média & 1,51 & 52,00 & 0,21 & 0,06 \\
Coeficiente de variação (\%) & 11,77 & 18,04 & 26,22 & 31,38 \\
Erro padrão da média (s) & 0,16 & 8,47 & 0,05 & 0,2 \\
\hline
\end{tabular}


descritiva dos dados correspondentes a percentagem de germinação, índice de velocidade de emergência (IVE) e peso da matéria seca da parte aérea e da raiz.

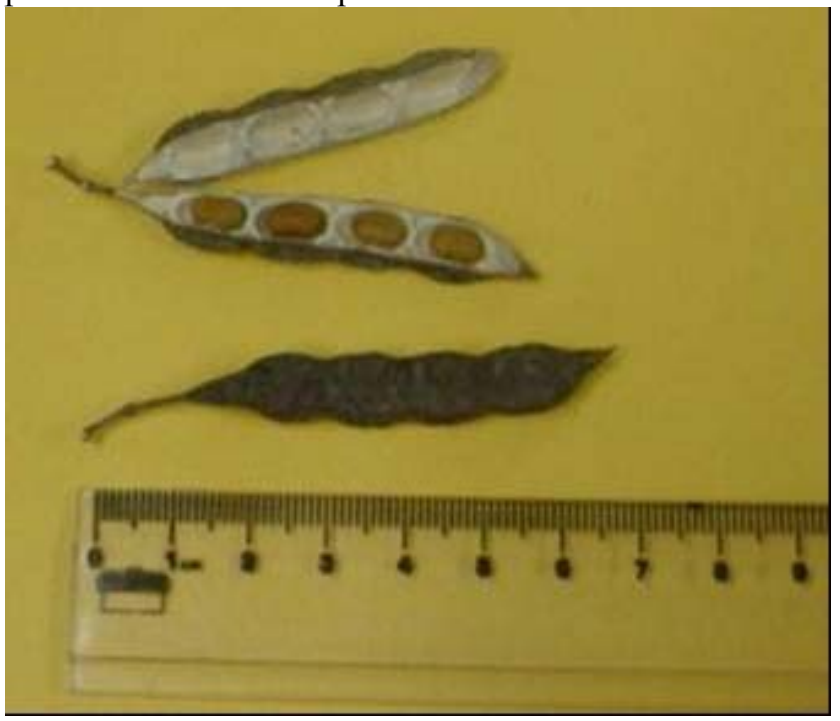

FIGURA 1. Frutos e sementes de Sesbania virgata.

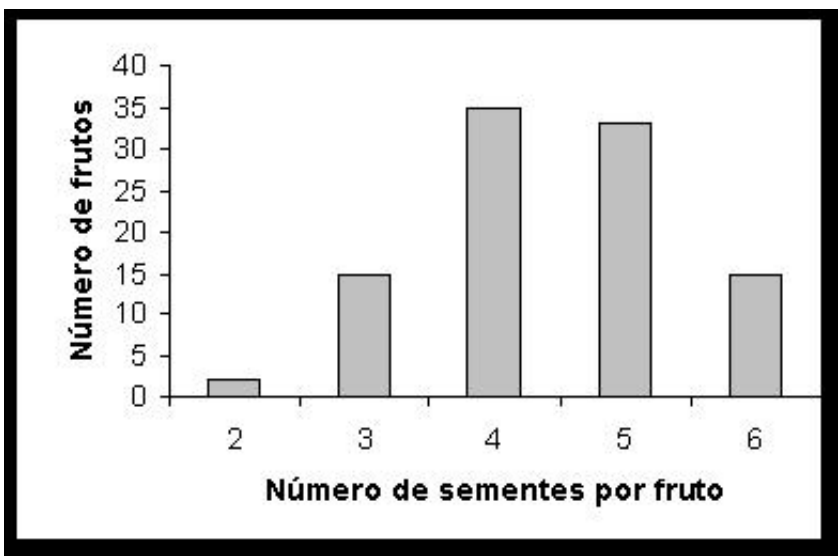

FIGURA 2. Distribuição do número de sementes por fruto de Sesbania virgata.

O peso médio da matéria seca por plântula da parte aérea e raiz encontra-se na Tabela 3.

A germinação da semente é do tipo epígea sendo que e o tegumento fica aderido aos cotilédones na fase inicial do crescimento da plântula. A radícula rompe o tegumento no segundo dia após a semeadura (Figura 4 a), caracterizando o início visível da germinação.

No segundo dia a radícula de cor esbranquiçada, apresentou comprimento variando de 5,57 a 15,19 mm, sendo que a espessura da base da radícula mediu $2 \mathrm{~mm}$, e a do ápice $1 \mathrm{~mm}$. Observou-se que no segundo dia que a radícula, que se afina da base para o ápice, ainda não apresenta raízes secundárias e o coleto é bem definido.
Parte do cotilédone ainda encontra-se recoberto pelo tegumento de cor marrom-casca (Figura 4b).

Sete dias após a semeadura o comprimento da raiz mediu $5,2 \mathrm{~cm}$, o hipocótilo $4,9 \mathrm{~cm}$ e o comprimento da plântula $12,7 \mathrm{~cm}$. Neste estádio a raiz apresentou rápido desenvolvimento, inicialmente engrossada, afinando em seguida com dilatação na base. Apresenta forma cilíndrica e é tenra, esbranquiçada, com a coifa também esbranquiçada, apresentando raízes secundárias, as quais são finas, curtas, tenras, cilíndricas e de cor branca. Posteriormente a raiz primária se transforma em sublenhosa, de cor branca ou marrom castanho. $\mathrm{O}$ epicótilo é tenro com base larga e de cor verde claro e não apresenta pelos. O colo é bem definido, devido à diferença de cor na área de transição entre o hipocótilo e a radícula. Inicialmente o hipocótilo é curto, curvando-se até tornar-se claro, tenro, cilíndrico, glabro e esverdeado. Os cotilédones são oblongos de ápices arredondados, opostos, de nervação pouco diferenciada, face dorsal verde clara e ventral verde escura formando um ângulo de aproximadamente $45^{\circ} \mathrm{com}$ o epicótilo. Nesta fase há também o aparecimento do primeiro par de protófilos. (Figura 4c).

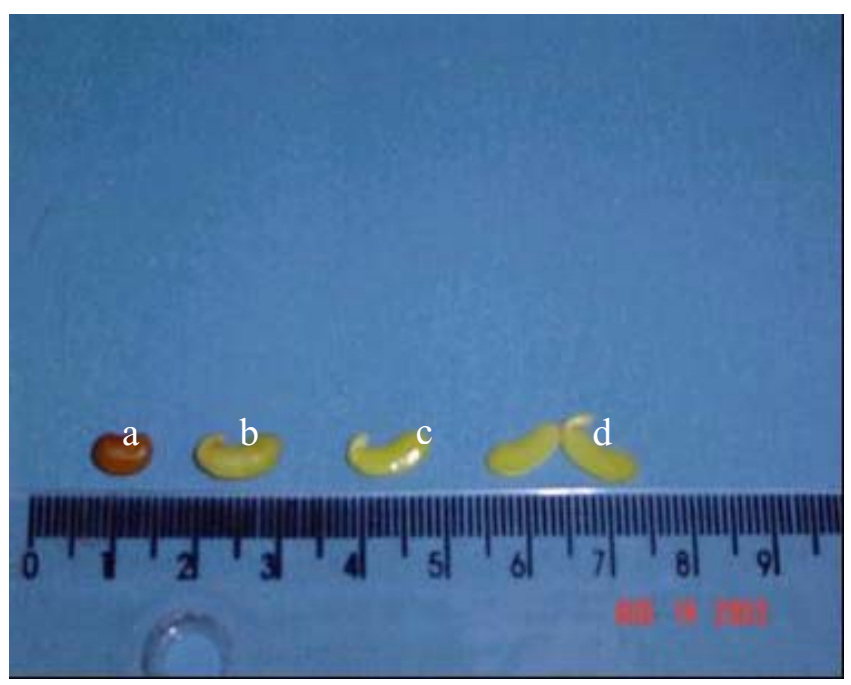

FIGURA 3. Semente de Sesbania virgata. Legenda: com tegumento (a), sem testa (b), sem endosperma (c) e embrião (d) de Sesbania virgata

No $8^{\circ}$ dia surgiu o segundo par de protófilos, de coloração verde-claro, arredondado, bordo contínuo, nervação peninérvia, sendo a nervura principal bastante evidente, impressa nas duas fases sendo as nervuras secundárias também bem visíveis. Treze dias após semeadura, o comprimento da raiz principal foi de $9,3 \mathrm{~cm}$, do hipocótilo 3,9 $\mathrm{cm}$ e do epicótilo $1,6 \mathrm{~cm}$ e o comprimento total é de $15 \mathrm{~cm}$. Nesta fase observou-se protófilos compostos com 4 a 9 pares de folíolos opostos, glabros, a 
ráquis é longa peciolada, apresentando pulvino e no ápice há uma pequena expansão laminar glabra. Os folíolos são pequenos, com a face dorsal de coloração verde clara e a face ventral verde escura, são opostos, ovóides, bordos contínuos, membranáceos, com nervação peninérvia e a nervura principal é bem evidente em ambas as faces, com nervuras secundárias pouco visíveis, caracterizando as plântulas jovens (Figura 4d).

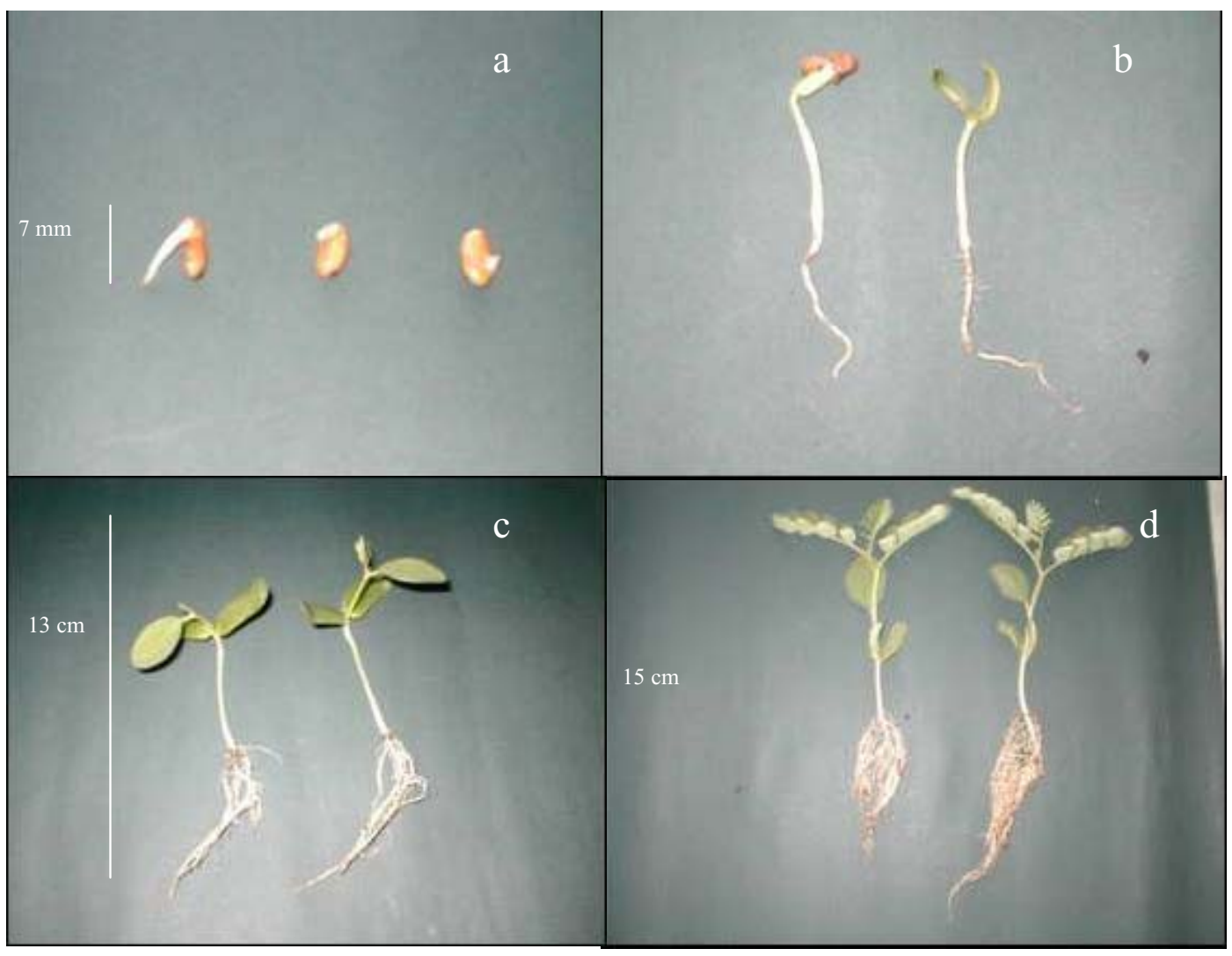

FIGURA 4. Estádios de germinação de Sesbariaia virgata. Legenda: (a) aparecimento da raiz primária; (b) cotilédones recobertos por tegumento de cor marrom e cotilédones livres; (c) aparecimento do primeiro par de protófilos; (d) plântulas jovens.

\section{CONCLUSÕES}

O fruto de Sesbania virgata é um legume indeiscente com comprimento médio de $5,8 \mathrm{~cm}$ e contendo de 2 a 6 sementes por fruto;

A semente de Sesbania virgata é reniforme, endospérmica, desprovida de tegma sendo o hilo e o estrofíolo facilmente distinguíveis; papilonáceo;

O embrião é cotiledonar, apical e invaginado

A germinação da semente é do tipo epígea;

A plântula jovem apresenta protófilos compostos com 4 a 9 pares de folíolos pequenos opostos e glabros com peciolo e pulvino, e no ápice há uma pequena expansão laminar glabra. A radícula é sublenhosa, de cor branca ou marrom castanho.

\section{REFERÊNCIAS}

BARROSO, M. B.; MARIM, M. P.; PEIXOTO, A.L.; ICHASO, C.L.F. Frutos e sementes. morfologia aplicada à sistemática de dicotiledôneas. Viçosa: UFV, 1999, 443p.

BELTRATI, C. M. Morfologia e anatomia das sementes de Trichilia elegans A. Juss (Meliaceae). Naturalia, São Paulo, v.9, p. 35-42, 1984.

COUTINHO, M. P. Crescimento de Sesbania virgata (Cav.) Pers em cavas de extração de argila. Campos dos Goytacazes. 2003. 54f. Dissertação (Mestrado em Produção Vegetal), Universidade Estadual do Norte Fluminense, 2003.

FERREIRA, R. A.; VIEIRA, M. G.G.C.; VON PINHO, É. V. R.; TONETTI, O. A. O. Morfologia da semente e de plântula e a avaliação da viabilidade de sementes de Sucupira-branca 
(Pterodon pubescens Benth - Fabaceae). Revista Brasileira de Sementes, Brasília, v. 23, n.1, 2001.

KUNIYOSHI,Y.S. Morfologia da semente e da germinação de 25 espécies arbóreas de uma floresta com araucária. Curitiba. 1983, 233f. Dissertação (Mestrado em Engenharia Florestal), Universidade Federal do Paraná, 1983.

MAGUIRE, J. D. Seeds of germination-aid selection and evaluation for seedling emergence and vigor. Crop Science, Madison, v-2, p. 176-177, 1962.

OLIVEIRA, E. C.; PEREIRA, T.S. Morfologia dos frutos alados em Leguminosae-Caesalpinioideae-Martiodendron Gleason, Peltophorum (Vogel) Walpers, Sclerolobium Vogel, Tachigalia aublet e Schizolobium Vogel. Rodriguesia, Rio de Janeiro, v.36, n. 60, p. 35-42, 1984.

POTT, A.; POTT, V. Plantas do pantanal. Brasília: EMBRAPA-
SPL, 1994. 320 p.

SAMÔR, O.J.M. Comportamento de mudas de Sesbania virgata e Anadenanthera macrocarpa, produzidas em recipientes e substratos, destinadas à recuperação de áreas degradadas pela extração de argila. Campos de Goytacazes. 1999. Dissertação (Mestrado em Produção Vegetal), Universidade Estadual do Norte Fluminense, 1999.

SANTOS, D. R.; MOREIRA, F. M. S.; SIQUEIRA, J. O. Fósforo, fungo micorrízico e rizóbio no crescimento, nodulação e fixação biológica do nitrogênio em Sesbania virgata (Cav.) e Sesbania rostrata (Bram). In: FERT'BIO. Anais... Caxambu, 1997. p. 772.

VIDAL, W. N.; VIDAL, M. R. R. Botânica organografia. 3.ed. Viçosa, Universidade Federal de Viçosa. 1995. 114p.

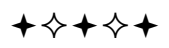

